\title{
Türkiye' de Sektör Bazında Enerji Tüketiminin Çevre Kirliliği Üzerine Etkisi
}

\author{
Cüneyt Yenal Kesbiça, Elif Tuğçe Bozduman ${ }^{\text {c }}$
}

Özet

Çalışmada 1998-2017 yılları arasında Türkiye'nin sektörel bazdaki enerji tüketiminin çevre kirliliği üzerine etkisi araştırılmıştır. Çalışmada sanayi, tarım, ulaşım, hane halkı ve bilgi-iletişim sektörleri arasındaki ilişki panel eşbütünleşme ve nedensellik testi ile analiz edilmiştir. Analizler sonucunda sektör bazında enerji tüketimi ile çevre kirliliği arasında uzun dönemli bir ilişki olmadığı ortaya çıkmıştır. Panel nedensellik sonuçlarına göre ise enerji tüketimi ve çevre kirliliği arasında tek yönlü nedensellik ilişkisi olduğu tespit edilmiştir.
Anahtar Kelimeler

\begin{tabular}{r}
$\mathrm{CO}_{2}$ Emisyonu \\
Enerji Tüketimi \\
Türkiye \\
Panel Nedensellik Testi \\
Makale Hakkında \\
\hline Geliş Tarihi: 01.03 .2021 \\
Kabul Tarihi: 21.06 .2021 \\
Doi: $10.18026 /$ cbayarsos.888607
\end{tabular}

\section{Effect of Energy Consumption on Environmental Pollution by Sector in Turkey}

\begin{abstract}
The study investigated whether Turkey's sectoral energy consumption had an impact on environmental pollution between 1998 and 2017. The sectors are industry, agriculture, transportation, household and information and communication sectors. The relationship between these sectors was examined by the panel cointegration and the panel causality test analysis and it has been revealed that there is no long-term relationship between energy consumption and environmental pollution on a sectoral basis. According to the panel causality results, it is observed that there is a one-way causality relationship.
\end{abstract}

Keywords

$\mathrm{CO}_{2}$ Emission

Energy Consumption

Turkey

Panel Causality Test

\begin{tabular}{r} 
About Article \\
\hline Received: 01.03.2021 \\
Accepted: 21.06.2021
\end{tabular}

Doi: $10.18026 /$ cbayarsos. 888607

b İletişim Yazarı: tugce.bozduman@cbu.edu.tr

a Prof. Dr., Manisa Celal Bayar Üniversitesi, İktisadi ve İdari Bilimler Fakültesi, ORCID ID: 0000-0001-8894-6439

c Arş. Gör., Manisa Celal Bayar Üniversitesi, İktisadi ve İdari Bilimler Fakültesi, ORCID ID: 0000-0002-6145-8571 


\section{Giriş}

Sanayi devriminin gerçekleşmesi ile birlikte ülkeler daha hızlı üretim yaparak ekonomilerini daha hızlı büyütmeye başlamışlardır. Sanayi devrimi ile birlikte kitle üretiminin yaygınlaşması, enerji tüketiminin sektörel bazda kullanımının ülke ekonomisi açısından önemini göstermiştir. Gelişmekte olan ülkeler özellikle 1990'l1 yıllardan itibaren küreselleşmenin etkisiyle gelişmiş ülkeler ile ekonomik anlamda yakınsamaya başlamıştır. Bununla birlikte, bu durum aynı zamanda küresel ısınma ve iklim değişikliğinin ortaya çımasına neden olmuştur. Bu nedenle, son yıllarda enerji tüketimi ile çevre kirliliği arasındaki ilişkiyi anlamak daha önemli hale gelmiştir (Kasman \& Duman, 2015).

Çevresel kirliliğin neden olduğu faktörlerden en önemlisi sanayileşmedir. Hammadde ve doğal kaynakların yoğun bir şekilde kullanılması nedeniyle sanayileşme çevresel bozulmayı beraberinde getirmiştir. Zira üretimle birlikte enerji kullanım oranının yükselmesi çevre kirliliğini de artırmıştır (Topallı, 2016).

Enerji ülkelerin ekonomik olarak kalkınmasında gerek arz gerekse talep yönünden stratejik bir önem taşımaktadır. Çünkü enerji tüm sektörler için en önemli girdi olmakla birlikte katma değer yaratarak üretim artışına yol açmaktadır. Bu durum enerji tüketiminin arz boyutunu göstermektedir (Öncel, Kırca, \& İnal, 2017). Hanehalkı ve ulaşım gibi sektörler ise enerji tüketiminin talep boyutunu oluşturmaktadır. Bu nedenle, sektörel bazda enerji tüketimi ülkeler için hem arz hem de talep unsuru olmakta ve her iki yönden de ülkeleri etkilemektedir.

Tüketilen enerjinin büyük bir bölümü fosil yakıtlardan oluşmaktadır. Bu durum da karbondioksit $\left(\mathrm{CO}_{2}\right)$ emisyonunun artmasına ve küresel iklim değişikliğine neden olmaktadır. Bu bağlamda, enerji tüketiminin fosil yakıtlardan karşılanması yerine çevreyi daha az kirleten enerji kaynaklarına yönelmek için ulusal ve uluslararası alanda önlemler alınmaya başlanmıştır (Ergün \& Polat, 2017). Enerji tüketiminin karbon salınımını artırması nedeniyle çevre olumsuz etkilenmektedir. Çünkü enerji tüketiminin daha yoğun olduğu sektörlerde karbon salınımı daha yüksek düzeyde olmaktadır. Bu nedenle çalışmada, Türkiye'de sektörel bazda enerji tüketiminin çevre üzerinde nasıl bir etkisi olduğu araştırılmaya çalışılmıştır.

Bu perspektifte, bu çalışmada Türkiye'de sanayi, tarım, ulaşım, hane halkı, bilgi ve iletişim sektörlerinde enerji tüketiminin çevre kirliliği üzerine etkisi panel veri analizi yöntemleri ile araştırılmıştır. 1998 ile 2017 yılları arasını kapsayan çalışmada veriler Uluslararası Enerji Ajansı'ndan (IEA) alınmıştır. Çalışmanın birinci bölümünde literatür incelenmiş, ikinci bölümünde analizlerin teorik çerçevesi ele alınmış, üçüncü bölümünde de değişkenler arasındaki ilişki ampirik olarak analiz edilmiştir.

\section{Literatür İncelemesi}

Literatürde enerji tüketimi ve çevre kirliliği üzerine yapılan çalışmalar ağırlıklı olarak ülke veya ülke grupları ile ilgilidir. Bununla birlikte, sektör bazında yapılan çalışmalar da literatürde yer almaktadır. Türkiye' de sektör bazında konuyla ilgili herhangi bir çalışmaya rastlanmamış olması bu çalışmanın yapılmasını gerekli kılmıştır. 
Tablo 1: Literatür Taraması

\begin{tabular}{|c|c|c|c|c|c|}
\hline Yazarlar & Ülke & Dönem & Değişkenler & $\begin{array}{l}\text { Kullanılan } \\
\text { yöntem }\end{array}$ & Nedensellik ilişkisi \\
\hline $\begin{array}{l}\text { Munir vd. } \\
\text { (2019) }\end{array}$ & ASEAN-5 & $1980-2016$ & $\begin{array}{l}\text { CO2 emisyonu, } \\
\text { enerji tüketimi, } \\
\text { ekonomik } \\
\text { büyüme }\end{array}$ & $\begin{array}{l}\text { Granger } \\
\text { nedensellik } \\
\text { testi }\end{array}$ & $\begin{array}{c}\mathrm{GDP} \rightarrow \mathrm{CO} 2, \\
\mathrm{GDP} \rightarrow \mathrm{EC}, \\
\mathrm{GDP} \leftrightarrow \mathrm{EC}\end{array}$ \\
\hline $\begin{array}{l}\text { Muhammad } \\
\text { (2019) }\end{array}$ & MENA & 2001-2017 & $\begin{array}{l}\text { CO2 emisyonu, } \\
\text { enerji tüketimi, } \\
\text { ekonomik } \\
\text { büyüme }\end{array}$ & $\begin{array}{l}\text { Panel } \\
\text { regresyon } \\
\text { modeli }\end{array}$ & $\begin{array}{c}\text { Tüm ülkelerde EC } \uparrow \\
\text { CO2 } \uparrow, \text { Gelişmiş } \\
\text { MENA ülkelerinde } \\
\text { EC } \uparrow \mathrm{CO} 2 \downarrow \text {, } \\
\text { Gelişmekte olan } \\
\text { MENA ülkelerinde } \\
\text { GDP } \uparrow \text { EC } \uparrow\end{array}$ \\
\hline $\begin{array}{c}\text { Wang ve } \\
\text { Dong (2019) }\end{array}$ & $\begin{array}{l}14 \text { Afrika } \\
\text { ülkesi }\end{array}$ & $1990-2014$ & $\begin{array}{c}\text { ekonomik } \\
\text { büyüme, ekolojik } \\
\text { ayak izi, } \\
\text { kentleşme ile } \\
\text { yenilenebilen ve } \\
\text { yenilenemeyen } \\
\text { enerji tüketimi }\end{array}$ & $\begin{array}{l}\text { Westerlund } \\
\text { eşbütünleşme, } \\
\text { Dumitrescu- } \\
\text { Hurlin } \\
\text { nedensellik } \\
\text { testi }\end{array}$ & $\begin{array}{c}\mathrm{GDP} \uparrow \mathrm{NRE} \uparrow \\
\mathrm{URPOP} \uparrow \mathrm{EF} \uparrow, \mathrm{RE} \uparrow \\
\mathrm{EF} \downarrow\end{array}$ \\
\hline $\begin{array}{l}\text { Yenisu } \\
(2018)\end{array}$ & Türkiye & $1960-2013$ & $\begin{array}{c}\text { ekonomik } \\
\text { büyüme, CO2 } \\
\text { emisyonu, } \\
\text { elektrik tüketimi }\end{array}$ & $\begin{array}{l}\text { VAR modeli, } \\
\text { Granger } \\
\text { nedensellik } \\
\text { testi }\end{array}$ & $\begin{array}{l}\mathrm{EC} \rightarrow \mathrm{CO} 2 \\
\mathrm{GDP} \rightarrow \mathrm{CO} 2\end{array}$ \\
\hline $\begin{array}{l}\text { Çetin ve } \\
\text { Yüksel } \\
(2018)\end{array}$ & Türkiye & $1960-2014$ & $\begin{array}{l}\text { enerji tüketimi ve } \\
\text { CO2 emisyonu }\end{array}$ & $\begin{array}{l}\text { Johansen- } \\
\text { Juselius ve } \\
\text { Philips- } \\
\text { Ouliaris } \\
\text { eşbütünleşme } \\
\text { yöntemi }\end{array}$ & $\mathrm{EC} \uparrow \mathrm{CO} 2 \uparrow$ \\
\hline $\begin{array}{c}\text { Alper ve } \\
\text { Alper (2017) }\end{array}$ & Türkiye & $1985-2014$ & $\begin{array}{c}\text { CO2 emisyonu, } \\
\text { ekonomik } \\
\text { büyüme ve } \\
\text { ham petrol } \\
\text { tüketimi }\end{array}$ & $\begin{array}{l}\text { ARDL sinir } \\
\text { testi }\end{array}$ & $\mathrm{GDP} \uparrow \mathrm{EC} \uparrow \mathrm{CO} 2 \uparrow$ \\
\hline Karış (2017) & Türkiye & $1960-2013$ & $\begin{array}{l}\text { enerji tüketimi, } \\
\text { CO2 emisyonu ve } \\
\text { ekonomik } \\
\text { büyüme }\end{array}$ & $\begin{array}{c}\text { Toda- } \\
\text { Yamamoto } \\
\text { nedensellik } \\
\text { yöntemi }\end{array}$ & $\begin{array}{c}\mathrm{EC} \leftrightarrow \mathrm{CO} 2 \\
\mathrm{GDP} \rightarrow \mathrm{CO} 2 \\
\mathrm{GDP} \rightarrow \mathrm{EC}\end{array}$ \\
\hline
\end{tabular}




\begin{tabular}{|c|c|c|c|c|c|}
\hline $\begin{array}{l}\text { Çemrek vd. } \\
\text { (2017) }\end{array}$ & $\begin{array}{c}\text { Karadeniz } \\
\text { Ekonomik } \\
\text { İşbirliği } \\
\text { Örgütü }\end{array}$ & 1993-2013 & $\begin{array}{l}\text { enerji tüketimi, } \\
\text { ekonomik } \\
\text { büyüme ve çevre } \\
\text { kirliliği }\end{array}$ & $\begin{array}{l}\text { Pedroni ve } \\
\text { Johansen panel } \\
\text { eşbütünleşme } \\
\text { testi, panel } \\
\text { regresyon } \\
\text { modeli }\end{array}$ & $\mathrm{EC} \uparrow \mathrm{CO} 2 \uparrow$ \\
\hline $\begin{array}{l}\text { Öncel vd. } \\
\text { (2017) }\end{array}$ & $\begin{array}{l}22 \text { OECD } \\
\text { ülkesi }\end{array}$ & $1990-2011$ & $\begin{array}{l}\text { elektrik tüketimi } \\
\text { ve ekonomik } \\
\text { büyüme }\end{array}$ & $\begin{array}{c}\text { Panel } \\
\text { nedensellik } \\
\text { analizi }\end{array}$ & $\mathrm{WH} \leftrightarrow \mathrm{GDP}$ \\
\hline $\begin{array}{l}\text { Topallı } \\
(2016)\end{array}$ & $\begin{array}{l}\text { Hindistan, } \\
\text { Çin, } \\
\text { Brezilya } \\
\text { ve Güney } \\
\text { Afrika }\end{array}$ & $1980-2010$ & $\begin{array}{c}\mathrm{CO}_{2} \text { emisyonu ve } \\
\text { ekonomik } \\
\text { büyüme }\end{array}$ & $\begin{array}{l}\text { Panel VECM } \\
\text { modeli }\end{array}$ & $\mathrm{GDP} \rightarrow \mathrm{CO} 2$ \\
\hline $\begin{array}{c}\text { Esso ve } \\
\text { Keho (2016) }\end{array}$ & $\begin{array}{l}\text { Seçilmiş } \\
12 \text { Afrika } \\
\text { ülkesi }\end{array}$ & 1971-2010 & $\begin{array}{l}\text { enerji tüketimi, } \\
\text { ekonomik } \\
\text { büyüme ve } \mathrm{CO}_{2} \\
\text { emisyonu }\end{array}$ & $\begin{array}{c}\text { Panel Grenger } \\
\text { nedensellik } \\
\text { yöntemi }\end{array}$ & $\begin{array}{l}\text { K1sa dönemde } \\
\text { GDP } \rightarrow \mathrm{CO} 2 \text {, uzun } \\
\text { dönemde EC ve } \\
\text { GDP } \rightarrow \text { CO2 }\end{array}$ \\
\hline $\begin{array}{l}\text { Saboori vd. } \\
\text { (2014) }\end{array}$ & $\begin{array}{l}\text { OECD } \\
\text { ülkeleri }\end{array}$ & $1960-2008$ & $\begin{array}{l}\text { enerji tüketimi, } \\
\text { ekonomik } \\
\text { büyüme ve } \mathrm{CO}_{2} \\
\text { emisyonu }\end{array}$ & $\begin{array}{l}\text { FMOLS } \\
\text { yöntemi }\end{array}$ & $\mathrm{EC} \uparrow \mathrm{GDP} \uparrow \mathrm{CO} 2 \uparrow$ \\
\hline $\begin{array}{l}\text { Pardo vd. } \\
\text { (2012) }\end{array}$ & Meksika & $1990-2008$ & $\begin{array}{l}\text { enerji tüketimi ve } \\
\text { CO2 emisyonu }\end{array}$ & $\begin{array}{c}\text { ayrıştırma } \\
\text { analizi yöntemi }\end{array}$ & $\mathrm{EC} \uparrow \mathrm{CO} 2 \uparrow$ \\
\hline $\begin{array}{l}\text { Pao ve Tsai } \\
\quad(2010)\end{array}$ & BRIC & 1971-2005 & $\begin{array}{l}\text { enerji tüketimi, } \\
\text { ekonomik } \\
\text { büyüme ve } \mathrm{CO}_{2} \\
\text { emisyonu }\end{array}$ & $\begin{array}{c}\text { Pedroni } \\
\text { eşbütünleşme } \\
\text { testi ve } \\
\text { Granger } \\
\text { nedensellik } \\
\text { testi }\end{array}$ & $\mathrm{EC} \uparrow \mathrm{CO} 2 \uparrow$ \\
\hline
\end{tabular}

Not: $\rightarrow$ Tek yönlü nedenselliği, $\leftrightarrow$ çift yönlü nedenselliği, $\uparrow$ artışı, $\downarrow$ azalışı ifade etmektedir.

GDP: Ekonomik Büyüme, EC: Enerji tüketimi, CO2: $\mathrm{CO}_{2}$ emisyonu, EF: Ekolojik ayak izi, WH: Elektrik tüketimi,

NRE: Yenilenemeyen enerji tüketimi, RE: Yenilenebilir enerji tüketimi, URPOP: Kentleşme

Literatür incelendiğinde yapılan çalışmaların ağırlıklı olarak CO2 emisyonu, enerji tüketimi ve ekonomik büyüme arasındaki ilişkiye yönelik olduğu görülmektedir. Çalışmalarda farklı ülkeler veya ülke grupları için yapılan nedensellik analizleri, enerji tüketiminin CO2 emisyonunu artırdığını göstermektedir.

\section{Veri Seti ve Yöntem}

1998-2017 dönemini kapsayan çalışmada yıllık Uluslararası Enerji Ajansı (IEA) verileri kullanılarak, Türkiye'deki beş alt sektörün (sanayi, tarım, ulaşım, hane halkı, bilgi ve iletişim) enerji tüketimlerinin (LNEC) $\mathrm{CO}_{2}$ emisyonu (LNCO2) üzerindeki etkisi analiz edilmiştir. Analizlerde değişkenlerin logaritmik değerleri kullanılmıştır. 
Tablo 2: Veri Setinin Tanıtımı

\begin{tabular}{ccc}
\hline Değişkenler & Açıklama & Kaynak \\
& Sektörlere ait toplam & Uluslararası Enerji \\
LNCO2 & CO2 emisyonu (bin ton & Ajansı (IEA) \\
& cektönden) & \\
LNEC & enerji tüketimi (bin ton & Uluslararası Enerji \\
& cinsinden) & Ajansı (IEA) \\
& & \\
\hline
\end{tabular}

Oluşturulan model şu şekildedir:

$$
\mathrm{LNCO} 2=\beta_{0}+\beta_{1} \mathrm{LNEC}_{\text {it }}+\mathrm{u}_{\mathrm{it}}
$$

1 nolu denklem enerji tüketiminin $\mathrm{CO}_{2}$ emisyonu üzerindeki etkisini göstermektedir. Modelde yer alan $\beta_{0}$ sabit terimi, $\beta_{1}$ LNEC'ye ait olan eğim katsayısını, $u$ ise hata terimini göstermektedir.

Çalışmada ilk olarak değişkenler arasında yatay kesit bağımlılı̆̆ı (birimler arası korelasyon) olup olmadığı Breusch-Pagan testi ile tespit edilmiştir. Değişkenler arasında yatay kesit bağımlılığının ortaya çıkması nedeniyle ikinci kuşak panel birim kök testi olan CIPS testi uygulanmıştır. Daha sonra değişkenlerin homojen olup olmadığını ölçmek amacıyla Swamy $S$ testi yapılmıştır. Değişkenler arasında uzun dönemli ilişkinin varlığını ortaya çıkarmak için Westerlund eşbütünleşme testi; nedenselliğin yönünün belirlenmesi için de DumitrescuHurlin panel nedensellik testi uygulanmıştır. Analizler STATA 16.0 programı kullanılarak yapılmıştır.

\section{Yatay Kesit Bă̆ımlılı̆̆ı Testi}

Birimler arasında ilişki olup olmadığını ölçmeye yarayan testlerden en sık kullanılanı Breusch-Pagan LM ve Pesaran CD testidir. Birim boyutunun zaman boyutundan $(\mathrm{N}>\mathrm{T})$ büyük olması durumunda $C D$ testi, aksi durumda ise LM testi daha doğru sonuçlar vermektedir (Tatoğlu, 2018). Breusch-Pagan LM testi şu şekilde formüle edilmiştir (Breusch \& Pagan, 1980):

$$
\mathrm{LM}=\mathrm{T} \sum_{i=1}^{N-1} \sum_{j=i+1}^{N} \hat{P}_{i j}^{2}
$$

Burada $\hat{P}_{i j}^{2}$, i ve j birimlerinin kalıntıları arasındaki korelasyon katsayısını ifade etmektedir. Boş hipotez yatay kesit bağımlılığ bulunmadığ bağımlılığı bulunduğu şeklindedir.

\section{Panel Birim Kök Testi}

Pesaran tarafından geliştirilen ve ikinci kuşak birim kök testlerinden Yatay Kesit Genişletilmiş Augmented Dickey-Fuller (CADF) ve Yatay Kesit Genişletilmiş Im, Pesaran ve Shin (CIPS) testleri yatay kesitler arasındaki ilişkiyi dikkate alarak hazırlanmıştır (Wang \& Dong, 2019). 
CADF ve CIPS testleri şu şekilde formüle edilmektedir (Pesaran, 2007):

$$
\begin{aligned}
& \mathrm{CADF}=\alpha_{\mathrm{i}}+\mathrm{b}_{\mathrm{i}} \mathrm{y}_{\mathrm{i}, \mathrm{t}-1}+\mathrm{c}_{\mathrm{i}} \bar{y}_{\mathrm{t}-1}+\mathrm{d}_{\mathrm{i}} \Delta \bar{y}_{\mathrm{t}}+\mathrm{e}_{\mathrm{it}} \\
& \mathrm{CIPS}=\mathrm{N}^{-1} \sum_{i=1}^{N} C A D F
\end{aligned}
$$

CADF birim kök testinde boş hipotez değişkenlerin durağan olmadığı, alternatif hipotez ise değişkelerin durağan olduğu şeklindedir. Paneli oluşturan her birim için $p$ istatistik değeri bulunmakta ve kritik değerler ile karşılaştırılmaktadır. CIPS testinde bulunan değerin mutlak değer hali kritik değerlerin üzerinde ise değişkenlerin durağan olduğu sonucuna varılmaktadır (Ergün \& Polat, 2017).

\section{Homojenlik Testi}

Swamy tarafından geliştirilen $S$ testi değişkenlerin homojen olup olmadığını belirlemek için kullanılmaktadır. Analiz sonuçlarının olasılık değerine bakılarak değişkenlerin homojen olup olmadığı belirlenmektedir. Boş hipotez değişkenlerin homojen olduğu, alternatif hipotez ise değişkenlerin homojen olmadığı şeklindedir. S Testi şu şekilde formüle edilmektedir (Swamy, 1970):

$$
\hat{S}=\mathrm{X}_{\mathrm{k}(\mathrm{N}-1)^{2}}=\sum_{\mathrm{I}=1}^{N}(\widehat{\beta} l-\bar{\beta})^{\prime} \widehat{V}_{\mathrm{i}}^{-1}(\widehat{\beta} \iota-\bar{\beta})
$$

Swamy S testi sonuçları ile değişkenlerin homojen olup olmadığı belirlenmekte ve buna göre eşbütünleşme ve nedensellik testleri seçilmektedir (Tatoğlu, 2018).

\section{Westerlund Eşbütünleşme Testi}

Westerlund tarafından geliştirilen test yatay kesitler arasındaki bağımlılığı dikkate almakta ve serilerin heterojen olması durumunda da kullanımına izin vermektedir. Westerlund eşbütünleşme testi şu şekilde formüle edilmektedir (Westerlund, 2005):

$$
\mathrm{WR}=\sum_{i=1}^{N} \sum_{t=1}^{T} \hat{E}_{\mathrm{it}^{2}}\left(\sum_{i=1}^{N} \hat{R}_{\mathrm{i}}\right)^{-1}
$$

$\mathrm{Bu}$ testin boş hipotezi eşbütünleşme ilişkisinin olmadığı̆, alternatif hipotezi ise eşbütünleşme ilişkisinin olduğu şeklindedir.

\section{Dumitrescu-Hurlin Panel Nedensellik Testi}

Değişkenler arasında nedensellik ilişkisinin olup olmadığı, varsa ilişkinin hangi yönde olduğunu belirlemek için nedensellik testleri kullanılmaktadır. Dumitrescu-Hurlin testi yatay kesit bağımlılı̆̆ı olan veya olmayan panellere heterojen olması şartı ile uygulanabilmektedir. Dumitrescu-Hurlin Nedensellik testi şu şekilde formüle edilmektedir (Dumitrescu \& Hurlin, 2012):

$$
\mathrm{Y}_{\mathrm{it}}=\alpha_{\mathrm{i}}+\sum_{j-1}^{J} \lambda_{\mathrm{i}} \mathrm{j} \mathrm{i}(\mathrm{t}-\mathrm{j})+\sum_{j-1}^{J} \beta_{\mathrm{i}} \mathrm{i} \mathrm{X}_{\mathrm{i}(\mathrm{t}-\mathrm{j})}+\mathrm{e}_{\mathrm{it}}
$$


$\mathrm{Bu}$ testin boş hipotezi nedensellik ilişkisi yoktur, alternatif hipotez ise nedensellik ilişkisi vardır şeklindedir.

\section{Elde Edilen Bulgular}

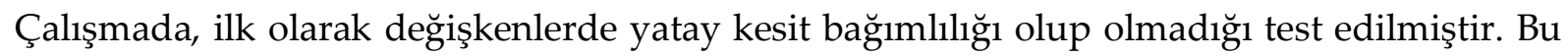
nedenle, Breusch-Pagan testi yapılmıştır.

Tablo 3: Yatay Kesit Bağımlılığı Test Sonuçları

\begin{tabular}{ccc}
\hline & Breusch-Pagan Testi & \\
Test & İstatistik değerleri & Olasılık değerleri \\
LM & 21.7 & $0.0167^{*}$ \\
LM adj* $^{*}$ & 6.081 & $0.0000^{*}$ \\
LM CD $^{*}$ & 2.219 & $0.0265^{*}$ \\
\hline
\end{tabular}

Not: $\left(^{*}\right) \% 5$ anlamlılık seviyesinde yatay kesit bağımlılı̆̆ını göstermektedir.

Tablo 3'te LM, LM adj ve LM CD testi sonuçlarına göre \%5 anlamlılık düzeyinde değişkenlerde yatay kesit bağımlılığının olmadığ şeklindeki olan boş hipotez reddedilmiştir. Diğer bir ifadeyle, değişkenler arasında yatay kesit bağımlılığı bulunmaktadır. Bu nedenle, ikinci kuşak birim kök ve eşbütünleşme testi kullanılmıştır.

Tablo 4: CADF Birim Kök Testi Sonuçları

\begin{tabular}{|c|c|c|c|c|c|c|}
\hline \multicolumn{7}{|c|}{ DÜZEY DEĞERLER } \\
\hline & t-bar & cv10 & cv5 & cv1 & $Z[t-b a r]$ & P-değeri \\
\hline LNCO2 & -2.296 & -2.210 & -2.340 & -2.600 & -1.228 & 0.110 \\
\hline LNEC & -2.126 & -2.210 & -2.340 & -2.600 & -0.860 & 0.195 \\
\hline \multicolumn{7}{|c|}{ BİRİNCİ FARKI ALINAN DEĞERLER } \\
\hline & t-bar & cv10 & cv5 & cv1 & $\mathrm{Z}[\mathrm{t}-\mathrm{bar}]$ & P-değeri \\
\hline LNCO2 & -3.721 & -2.210 & -2.340 & -2.600 & -4.323 & $0.000^{*}$ \\
\hline LNEC & -3.329 & -2.210 & -2.340 & -2.600 & -3.472 & $0.000^{*}$ \\
\hline
\end{tabular}

Not: (*) \%1 anlamlılık seviyesinde durağanlığı göstermektedir.

CADF birim kök testi sonuçlarına göre, her iki değişkenin de düzey değerlerde olasılık değeri \%1 anlamlılık seviyesinden büyük olduğu için birim kök içermektedir. Yani değişkenler düzeyde durağan değildir. Değişkenlerin birinci farkları alındığında her iki değişkenin de durağanlaştı̆̆ görülmektedir.

CIPS birim kök testinde serilerin durağan olabilmesi için çıan CIPS testi sonuçlarının mutlak değerinin, \%1, \%5 ve \%10 anlamlılık seviyesinde belirlenen kritik değerlerden büyük olması gerekmektedir. 
Tablo 5: CIPS Birim Kök Testi Sonuçları

\begin{tabular}{|c|c|c|c|c|}
\hline \multicolumn{5}{|c|}{ DÜZEY DEĞERLER } \\
\hline \multirow{3}{*}{ LNEC } & CIPS $=-1.949$ & $\mathrm{~N}, \mathrm{~T}=(5,20)$ & & \\
\hline & \multirow{2}{*}{ Kritik Değerler } & $10 \%$ & $5 \%$ & $1 \%$ \\
\hline & & -2.21 & -2.34 & -2.6 \\
\hline \multirow{3}{*}{ LNCO2 } & CIPS $=-2.277$ & $\mathrm{~N}, \mathrm{~T}=(5,20)$ & & \\
\hline & \multirow{2}{*}{ Kritik Değerler } & $10 \%$ & $5 \%$ & $1 \%$ \\
\hline & & -2.21 & -2.34 & -2.6 \\
\hline \multicolumn{5}{|c|}{ BİRINCİ FARKI ALINAN DEĞERLER } \\
\hline \multirow{3}{*}{ LNEC } & CIPS $=-4.080$ & $\mathrm{~N}, \mathrm{~T}=(5,20)$ & & \\
\hline & \multirow{2}{*}{ Kritik Değerler } & $10 \%$ & $5 \%$ & $1 \%$ \\
\hline & & -2.21 & -2.34 & -2.6 \\
\hline \multirow{3}{*}{ LNCO2 } & CIPS $=-4.337$ & $\mathrm{~N}, \mathrm{~T}=(5,20)$ & & \\
\hline & \multirow{2}{*}{ Kritik Değerler } & $10 \%$ & $5 \%$ & $1 \%$ \\
\hline & & -2.21 & -2.34 & -2.6 \\
\hline
\end{tabular}

Tablo 5'te görüldüğü gibi, değişkenlerin düzey değerlerinde çıkan CIPS testi sonuçları mutlak değer olarak kritik değerlerin altındadır. Bu nedenle, değişkenler düzey değerlerinde durağan değildir yani birim kök içermektedir. Değişkenlerin birinci farkları alındığında ise çıkan CIPS testi sonuçları mutlak değer olarak \%1, \%5 ve \%10 anlamlılık seviyesinde belirlenen kritik değerlerin üstünde olduğu için her iki değişkenin de durağanlaştığ1 görülmektedir.

Tablo 6: Swamy S Testi Sonuçları

\begin{tabular}{|c|c|c|c|c|c|c|}
\hline LNCO2 & Katsayı & Std. Hata & Z değeri & $P>|z|$ & \multicolumn{2}{|c|}{ [95\% Güven Aralığı] } \\
\hline LNEC & 1122496 & .265947 & 4.22 & 0.000 & .60125 & 1643743 \\
\hline LNFARKCO2 & .5547048 & .1015787 & 5.46 & 0.000 & .3556143 & .7537954 \\
\hline LNFARKEC & -.4916586 & .2966199 & -1.66 & 0.097 & -1073023 & .0897057 \\
\hline _cons & -.370304 & 2667037 & -0.14 & 0.890 & -5597601 & 4856993 \\
\hline \multicolumn{4}{|c|}{ Parametre sabitliği: $\quad$ chi2 $(16)=24409.36$} & \multicolumn{3}{|c|}{ Prob $>$ chi $2=0.0000^{*}$} \\
\hline
\end{tabular}

Not: $\left(^{*}\right) \% 1$ anlamlılık düzeyinde değişkenlerin heterojenliğini göstermektedir.

Swamy S testi sonuçları incelendiğinde (Tablo 6), değişkenlerin homojen olduğu şeklindeki boş hipotez \%1 anlamlılık seviyesinde reddedilmiştir. Değişkenlerin homojen olmadığı, birimden birime değiştiği yani heterojen olduğu alternatif hipotez kabul edilmektedir.

Değişkenler heterojen olduğu için eşbütünleşme testlerinden ve nedensellik testlerinden heterojen panellere uygun olan testler yapılmalıdır. Bu nedenle, değişkenler arasındaki uzun dönemli ilişkiyi araştırmak için Westerlund eşbütünleşme testi yapılmıştır. Değişkenler arasında nedensellik olup olmadığını, varsa nedenselliğin yönünü belirlemek için de Dumitrescu-Hurlin nedensellik testi yapılmıştır. 
Tablo 7: Westerlund Panel Eşbütünleşme Testi

\begin{tabular}{cccc}
\hline Test & t- istatistik değeri & $\begin{array}{c}\text { z-istatistik } \\
\text { değeri }\end{array}$ & olasılık değeri \\
Gt & -2194 & -1008 & 0.157 \\
$\mathrm{Ga}$ & -9511 & -0.953 & 0.170 \\
$\mathrm{Pt}$ & -2213 & 1070 & 0.858 \\
$\mathrm{~Pa}$ & -3636 & 0.351 & 0.637 \\
\hline
\end{tabular}

Not: Testler sabitli olarak uygulanmıştır.

Değişkenlerin aynı düzeyde durağan olmaları, eşbütünleşme testi uygulanmasına imkân sağlamıştır. Westerlund panel eşbütünleşme testi sonuçlarına göre (Tablo 7), paneli oluşturan birimler arasında eşbütünleşik ilişki yoktur şeklinde belirlenen boş hipotez reddedilememiştir. Çıkan olasılık değerleri \%1, \%5 ve \%10 anlamlılık seviyesinden büyük olduğu için Ho hipotezi kabul edilmiştir. Değişkenler arasında eşbütünleşik ilişki bulunmamaktadır.

Tablo 8: Dumitrescu-Hurlin Panel Nedensellik Test Sonuçları

\begin{tabular}{c}
\hline LNEC $\rightarrow$ LNCO2 \\
Optimal Gecikme Uzunluğu (AIC): 1 \\
W-bar $=1.0396$ \\
Z-bar $=0.0625 \quad($ p-değeri $=0.9501)$ \\
Z-bar tilde $=-0.1278 \quad($ p-değeri $=0.8983)$ \\
H0: Enerji tüketimi karbondioksitin nedeni değildir. \\
H1: Enerji tüketimi karbondioksitin nedenidir. \\
LNCO2 $\rightarrow$ LNEC \\
Optimal Gecikme Uzunluğu (AIC): 1 \\
W-bar $=4.9598$ \\
Z-bar $=6.2610 \quad\left(\right.$-değeri $\left.=0.0000^{*}\right)$ \\
Z-bar tilde $=4.7232 \quad\left(\right.$ p-değeri $\left.=0.0000^{*}\right)$
\end{tabular}

H0: Karbondioksit enerji tüketiminin nedeni değildir.

H1: Karbondioksit enerji tüketiminin nedenidir.

Not: Gecikme uzunluğu 1 olarak alınmış ve optimal gecikme uzunluğu Akaike

bilgi kriterine göre belirlenmiştir. ${ }^{*}$ ) \%1 anlamlılık seviyesini göstermektedir.

Değişkenler arasındaki nedensellik ilişkisi incelendiğinde (Tablo 8), optimal gecikme uzunluğunun 1 olarak alındığı, LNEC'den $\mathrm{LNCO}_{2}$ 'ye bir nedensellik ilişkisi bulunmadığı, $\mathrm{LNCO}_{2}$ 'den $\mathrm{LNEC}^{\prime}$ ye doğru bir nedensellik ilişkisi bulunduğu görülmektedir. Diğer bir ifadeyle, enerji tüketiminden $\mathrm{CO}_{2}$ emisyonuna doğru tek yönlü nedensellik ilişkisi bulunmaktadır. 


\begin{abstract}
Sonuç
Ülkelerin yüksek ekonomik büyüme oranlarını gerçekleştirebilmesi ve sürdürülebilir kılabilmesi sektörel anlamda üretim ve verimlilik düzeylerini artırabilmelerine bağlıdır. Zira gerek tarım gerekse sanayi sektöründe üretim kapasitesi artışına verimlilik artışının eşlik etmesi ülkelerin ekonomik büyüme oranlarını potansiyel düzeylerinde gerçekleşmesini sağlayacaktır. Bu bağlamda, sektörlerin büyüyebilmesi için daha çok enerji kullanımına gerek duyulmaktadır. Enerji kullanımımın artışı sektörlerin büyüyerek üretim kapasitesini artırmasını sağlarken aynı zamanda çevre kirliliğini de artırmaktadır.

Gelişmekte olan ülkeler arasında yer alan Türkiye de gelişmişlik düzeyini yükseltmek için ekonomik büyüme hızını artırmak ve sürdürülebilir kılmak mecburiyetindedir. Bu bağlamda, Türkiye'nin yüksek ekonomik büyüme hızına ulaşabilmesi, tüm sektörlerde kullandığı girdi miktarının artırılması anlamına gelmektedir. Bu durum sektörlerde enerji tüketimindeki artışı kaçınılmaz hale getirmiştir. Keza, 1998 yılında 48.805 bin ton olan enerji tüketimi 2017 yılında 100.057 bin tona yükselmiştir. Diğer bir deyişle, 1998-2017 yılları arasında Türkiye'nin enerji tüketimi \%107 oranında artmıştır. Haliyle, bu da çevre kirliliğini beraberinde getirmektedir. Bu nedenle, bu çalışmada Türkiye'nin sektörel bazda enerji tüketiminin çevre kirliliği üzerine etkisi araştırılmıştır.

Çalışmada öncelikle değişkenler arasında yatay kesit bağımlılığının varlığı tespit edilmiş ve ikinci nesil birim kök testi uygulanmıştır. Bunun sonucunda, değişkenlerin düzey değerlerinde değil birinci fark değerlerinde durağan olduğu ortaya çıkmıştır. Değişkenlerin aynı düzeyde durağan olması eşbütünleşme testi yapılmasını gerekli kılmıştır. Eşbütünleşme testi sonucunda sektörel bazda enerji tüketimi ile $\mathrm{CO}_{2}$ emisyonu arasında eşbütünleşik ilişkinin olmadığ enerji tüketimi arasında tek yönlü nedensellik ilişkisinin bulunduğu ortaya çımıştır. Diğer bir ifadeyle, sektörel anlamda enerji tüketiminin artışının $\mathrm{CO}_{2}$ salınımını artırarak çevre kirliğine neden olduğu tespit edilmiştir.

Yurtiçi enerji arzı enerji talebini karşılamakta yetersiz olan Türkiye'de ithalat kaçınılmaz olmaktadır. Türkiye'nin ağırlıklı olarak enerji ithalatına bağımlı bir şekilde üretim yaptığı göz önüne alındığında, ucuz ama çevreyi daha fazla kirleten enerji kaynakları yerine, çevreyi daha az kirleten (rüzgar, güneş, elektrik vb.) enerji kaynaklarına yönelmesi gerekmektedir. Türkiye'de özellikle yenilenebilir enerji kaynakları kullanılarak enerji üretiminin artırılması hem üretimin daha temiz enerji kaynakları ile yapılmasını hem de çevre kirliliğinin neden olduğu hasarların azalmasını mümkün kılacaktır. Özellikle sanayi ve ulaşım sektöründe enerji tüketiminin azaltılması çevre kirliliğinin de azalmasına oldukça büyük katkı sağlayacaktır. Bu perspektifte, vergi ve teşvik politikalarının, yasa ve yönetmeliklerin çevre ve yenilenebilir enerji kaynakları odaklı oluşturulması gerekmektedir.
\end{abstract}




\section{Kaynakça}

Alper, F. Ö., \& Alper, A. E. (2017). Karbondioksit Emisyonu, Ekonomik Büyüme, Enerji Tüketimi İlişkisi: Türkiye İçin Bir ARDL Sınır Testi Yaklaşımı. Sosyoekonomi Dergisi, 25(33), 145-156.

Breusch, T. S., \& Pagan, A. (1980). The Lagrange Multiplier Test and its Applications to Model Specification in Econometrics. Review of Economic Studies, 239-253.

Dumitrescu, E. I., \& Hurlin, C. (2012). Testing for Granger non-causality in heterogeneous panels. Economic Modelling, 29(4), 1450-1460.

Ergün, S., \& Polat, M. A. (2017). G7 Ülkelerinde CO2 Emisyonu, Elektrik Tüketimi ve Büyüme İlişkisi. Siyaset, Ekonomi ve Yönetim Araştırmaları Dergisi, 5(2), 257-272.

Karış, Ç. (2017). Türkiye'de Enerji Tüketimi, CO2 Emisyonu ve Ekonomik Büyüme Arasındaki İlişki: 1960-2013 Dönemi. Kocaeli Üniversitesi Sosyal Bilimler Dergisi, 34, 169197.

Kasman, A., \& Duman, Y. S. (2015). CO2 Emission, Economic Growth, Energy Consumption, Trade and Urbanization in New EU member and Candidate Countries: A Panel Data Analysis. Economic Modelling, 97-103.

Öncel, A., Kırca, M., \& İnal, V. (2017). Elektrik Tüketimi ve Ekonomik Büyüme İlişkisi: OECD Ülkelerine Yönelik Zamanla Değişen Panel Nedensellik Analizi. Maliye Dergisi, 398-420.

Pesaran, M. H. (2007). A Simple Panel Unit Root Test in the Presence of Cross-Section Dependence. JOURNAL OF APPLIED ECONOMETRICS, 265-312.

Swamy, P. A. (1970). Efficient Inference in a Random Coefficient Regression Model. Econometrica Journal, 38(2), 311-323.

Tatoğlu, F. Y. (2018). Panel Zaman Serileri Analizi. İstanbul: Beta Yayınları.

Topallı, N. (2016). CO2 Emsyonu ve Ekonomik Büyüme Arasındaki İlişki: Hindistan, Çin, Brezilya ve Güney Afrika için Panel Veri Analizi. Çankırı Karatekin Üniversitesi İktisadi ve İdari Bilimler Fakültesi Dergisi, 6(1), 427-447.

Wang, J., \& Dong, K. (2019). What drives environmental degradation? Evidence from14 SubSaharan African countries. Science of the Total Environment, 165-173.

Westerlund, J. (2005). New Simple Tests for Panel Cointegration. Econometric Reviews , 297316.

Yenisu, E. (2018). Enerji Tüketimi, CO2 Emisyonu ve Ekonomik Büyüme İlişkisi: Türkiye Örneği. Van YYÜ İIBBF Dergisi, 3(5), 9-29. 